\title{
The HIV/AIDS epidemic in Brazil: three decades
}

The Brazilian government's policy to respond to AIDS with the universal, free supply of antiretroviral drugs and medications for opportunistic diseases through the public health system was heavily questioned, especially when the policy was first implemented in the 1990s. The program's success is now acknowledged internationally, due not only to this key component, but also to interaction with other government ministries, in constant dialogue with social movements and the scientific community. Universal access to antiretroviral therapy (ART) has led to a significant reduction in morbidity and mortality.

However, the program still faces many difficulties in maintaining long-term sustainability. In addition to budget issues, care for persons living with HIV/AIDS poses major challenges. Prevention efforts also need to be intensified. Thirty years since the first AIDS cases in Brazil, young people are now living with a disease for which there is specific treatment, without having experienced the high AIDS case fatality at the beginning of the epidemic. And with the increase in survival, quality of life for persons living with HIV/AIDS has become increasingly relevant.

This Supplement, sponsored by the Department of STD, AIDS, and Viral Hepatitis, under the Ministry of Health, includes articles on issues related to the HIV/AIDS epidemic since the consolidation of universal access to ART in Brazil. Two articles discuss the major strides in increasing survival among both adults and children. Despite undeniable success, the results of a case-control study presented here show that many of the factors associated with AIDS deaths could be prevented.

As for aspects related to quality of life, the article with findings from a study on patients undergoing ART shows that a major proportion of these patients enjoy good selfrated health, although their concerns about the future and symptoms of depression are still problems that need to be overcome.

Another article proposes three different ways of measuring adherence to ART that are appropriate for monitoring by health services and allow early identification of patients at risk of treatment failure.

From the epidemiological point of view, the two studies with results from behavioral surveillance studies suggest problems in the adoption of safe sex practices. The first, featuring information collected in a household survey, reveals women's increased vulnerability in various areas. Meanwhile, the study on military conscripts shows a decrease in regular condom use.

A study whose main objective was to evaluate the Ministry of Health's strategies to stimulate the municipal response to the HIV/AIDS epidemic shows that these strategies have in fact contributed to the strides achieved.

On methodological issues, two articles present appropriate probabilistic sampling techniques for most-at-risk populations and discuss their application in Brazil. Another article provides a review of serological methods for estimating HIV incidence, based on data from cross-sectional studies. Currently, the estimation of HIV incidence in different groups in the Brazilian population is crucial for understanding the epidemic's recent dynamics, contributing to the development of prevention strategies, monitoring the ongoing interventions under way, and evaluating the impact of universal access to treatment.

Célia Landmann Szwarcwald

Instituto de Comunicação e Informação Científica e Tecnológica

em Saúde, Fundação Oswaldo Cruz, Rio de Janeiro, Brasil.

celials@cict.fiocruz.br
Euclides Ayres de Castilho

Faculdade de Medicina, Universidade de São Paulo,

São Paulo, Brasil.

castil@usp.br 